\title{
DEMİRYOLU ÇİZELGELEME PROBLEMİNÍN MODELLENMESİ VE ÇÖZÜMÜ
}

\author{
Nazlı GÜLTEKIN, Tamer EREN \\ Kırıkkale Üniversitesi, Endüstri Mühendisliği Bölümü, Ankara Yolu, 71451, KIRIKKALE \\ nazli.g 87@hotmail.com, tameren@hotmail.com
}

(Geliş/Received: 22.08.2013; Kabul/Accepted: 13.03.2014)

ÖZET

$\mathrm{Bu}$ çalışmada, trenlerdeki gecikmelerle ilgili sorunlara çözüm bulmak için önerilerde bulunulmuştur. $\mathrm{Bu}$ makalede ilk olarak 16 istasyonlu 6 trenin çalıştığı Yeniçubuk-Çetinkaya demiryolu hattı ele alınmış ve gecikmeleri azaltmak için 0-1 tamsayll programlama modeli önerilmiştir. Bu model sonucunda, elde edilen verilerle tren hareket saatleri düzenlenmiş ve gecikmelerde $\% 81,59$ oranında iyileşme sağlanmıştır. Ayrıca ele alınan toplam $240 \mathrm{~km}$ 'lik hat için, trenlerin gecikmesine yol açan 31 km'lik kısmında çift hatta dönüştürülmesi durumunda gecikmelerin \% 96,52 oranında iyileştirme olacağı benzetim çalışması ile gösterilmiştir.

Anahtar Kelimeler: Demiryolu çizelgeleme, gecikme, 0-1 tamsayılı programlama, benzetim

\section{MODELLING AND SOLVING THE RAILWAY SCHEDULING PROBLEM}

\begin{abstract}
In this study, to find solutions to problems related to delays in train suggestions were made. In this paper, first of all Yeniçubuk-Çetinkaya railway which have 16 stations and 6 trains worked on, was handled and 0-1 integer programming was proposed to reduce the delays. Train time schedules were regulated with data obtained from solution of this model and delays have been improved by $81.59 \%$. Also, it was shown, that the delays can be improved $96.52 \%$ by simulating the case of changing $31 \mathrm{~km}$ railway line out of totally $240 \mathrm{~km}$ with double railway line.
\end{abstract}

Key Words: Railway scheduling, tardiness, 0-1 integer programming, simulation

\section{GIRISŞ (INTRODUCTION)}

Literatürde çizelgeleme problemleri birçok amaç fonksiyonu için incelenmiştir[1]. Gecikmeyi minimize etmekte, araştırmacıların en çok ilgilendiği konulardan biridir[2,3]. Bu çalışmada da demiryolu taşımacılığındaki gecikme problemi ele alınmıştır.

Demiryolu yolcu ve yük taşımacılığı özellikle son yüzyılda oldukça büyük öneme sahiptir. Gelecekte de yüksek hızlı tren hatlarıyla öneminin daha da artacağ 1 düşünülmektedir. Ülkemizde demiryollarının hat uzunluğu, 9642 km'si ana hat ve $2358 \mathrm{~km}$ 'si tali hat olmak üzere toplam $12000 \mathrm{~km}$ 'dir. Bu yol uzunluğu bazı ülkeler ile kıyaslandığında yetersiz olduğu görülecektir. Ülkemizde demiryollarının hat uzunluğu bakımından yetersiz olmasının yanı sıra, yolun \% 98,2'sinin tek hatlı olması ayrı bir olumsuzluk faktörü olarak ortaya çıkmaktadır. Aynı hat üzerinde sadece bir tren olacağından, karşıdaki tren istasyonda beklemek zorunda kalmaktadır. Planlı beklemeler dışında, plansız gecikmeler olması durumunda da o hat üzerimde çalışan tüm tren seferlerinde gecikmeler yaşanabilmektedir[4].

$\mathrm{Bu}$ çalışmada da demiryolu taşımacılığında önemli problemlerden biri olan gecikmeler konusunda iki çözüm önerisi sunulmuştur. İlk çözüm yaklaşımı, 0-1 tamsayılı programlama modeli kullanılarak tren hareket saatlerinin düzenlenmesiyle gecikmelerin azaltılabileceği gösterilmiştir. İkinci çözüm yaklaşımında ise en çok gecikme yaşanan tek hatlı demiryolu hatlarının çift hatlı hale getirilmesi durumunda gecikmelerdeki iyileşme benzetim çalışmasıyla gösterilmiştir. İlk çözüm yöntemi maliyet gerektirmeyen bir uygulama olmasına rağmen ikinci çözüm yöntemi önemli maliyet gerektirmektedir[4]. 
Çalışmanın planı şu şekildedir: İkinci bölümünde demiryolu çizelgeleme konusunda yapılan çalışmalardan bahsedilmiştir. Önerilen matematiksel model üçüncü bölümde verilmiştir. Örnek uygulama dördüncü bölümde anlatılmıştır. Son bölüm olan beşinci bölümde ise yapılan çalışmanın sonuçları anlatılmış ve gelecekte yapılabilecek çalışmalar hakkında önerilerde bulunulmuştur.

\section{DEMİRYOLU CIZZELGELEME İLE İLGÍLI LITERATÜRDEKI CALISMALAR (RAILWAY SCHEDULING STUDIES IN THE LITERATURE)}

Demiryolu çizelgeleme konusunda yapılan literatür araştırması sonucunda konuyla ilgili çok sayıda çalışma bulunmuştur. Charnes ve Miller [5], demiryolunun mevcut çizelgeleme problemlerinde yöneylem araştırmasının bazı tekniklerini uygulama girişimi amacıyla, yük treni hareketlerinin çizelgelemesinde dinamik programlama modeli kullanmışlardır. Petersen ve Taylor [6], demiryolu hattı için genel amaçlı bir model önerisi sunmuşlardır. Kraay vd. [7], uluslararası demiryollarında hız denetimi konusunda tren çizelgeleme problemi için model oluşturarak alternatif çözüm önerileri geliştirmişlerdir. Higgins ve Kozan [8], Avustralya demiryollarında tek hatlarda çizelgeleme için karışık tamsayılı programlama modeli kullanmışlardır. Cordeau vd. [9], demiryolu çizelgeleme problemlerinde sıkça kullanılan optimizasyon modellerini araştırmışlardır. Linder ve Zimmermann [10], Hollanda anahatlarında tren çizelgelemesi yapmış ve konuyla ilgili problemde doğrusal programlama modeli ve dal-sınır metodu kullanmışlardır. Caprara [11], belirli bir zaman aralığında istasyonlardaki tren hareketlerine karşılık gelen düğümler için bir şebeke teori formülasyonu üretmiştir. Lee ve Chen [12], Tayvan Demiryolu İdaresi için sürücü çizelgeleme probleminde genetik algoritma ile iki çözüm yaklaşımı geliştirmişlerdir. Matematiksel programlama modeli (seyyar satıcı problemi modeli) ile de çözülen problem sonuçlar ve çözüm süreleri açısından kıyaslanmıştır. Ahuja vd. [13], gerçek yaşam tren çizelgeleme problemlerini ele almışlardır ve uygulamada 0-1 karışık tamsayılı programlama modeli kullanmışlardır. Chen ve Chui [14], tamsayılı programlama modeli kullanarak demiryolunda ekip çizelgeme yapmışlardır. Demiryolu hattında verimi arttırmak için vardiya planlaması ve çalışma saatleri üzerine uygun bir zaman çizelgesi oluşturulmuştur. Aydın [15], tren çizelgelemesi problemi üzerine tamsayilı model şeklinde formüle edilen, sezgisel bir indirgeme algoritması geliştirmiştir. Reimann ve Leal [16], tek hat üzerinde farklı hızlarla seyahat eden trenlerin çizelgeleme problemini karınca kolonisi algoritması kullanılarak çözmüşlerdir. Danescu [17], Romanya ve Moldova'da aynı hattaki yük ve yolcu trenlerinde trafik yükünü azaltmak için matematiksel model geliştirerek uygulama yapmıştır.
$\mathrm{Bu}$ çalışmada da demir yollarında gecikmeleri azaltmak için çözüm yaklaşımları geliştirilmiştir.

\section{3. ÖNERILLEN $\quad 0-1 \quad$ TAMSAYILI PROGRAMLAMA MODELI (PROPOSED 0-1 INTEGER PROGRAMMING MODEL)}

Uygulamada 6 trenin sefer yaptığ 16 istasyonlu tek hat ele alınmıştır ve 0-1 tamsayılı programlama modeli kurulmuştur. Modelde Aydın [15]'ın çalışmasından esinlenilmiştir. Modelde, Aydın [15]'ın çalışmasına benzer olarak; trenlerin hatta giriş zamanlarının ayarlanmasıyla son varış noktalarındaki gecikmelerinin toplamını en aza indirmek amaçlanmıştır. $\mathrm{Bu}$ amaca göre her iki modelde de trenler, kalkış istasyonundan belirtilen zamandan önce hareket edemezler, ancak çatışma çözümleri dolayısıyla başlangıç istasyonlarında bekletilmeleri söz konusu olabilir.

Çözüm yöntemi olarak Aydın [15] çalışmasından farklı bir yol izlenmiștir. Aydın [15] çalışmasında tren sayısıyla bağlantılı problem karmaşıklığını önlemek için sezgisel bir indirgeme algoritması geliştirilmiştir. $\mathrm{Bu}$ çalışmada ise problem boyutu düşünülerek Lindo 6.1 kullanılmıştır.

Bu modelde;

$i, j, m, t_{i}$ Tren indeksleri

$C_{i} \quad$ İstasyon kapasitesi

$s \quad$ İstasyon indeksi

$E \quad$ Doğuya giden trenlerin kümesi

$W \quad$ Batıya giden trenlerin kümesi

$S \quad$ İstasyonlar kümesi

$a_{i s} \quad i$ numaralı trenin $s$ numaralı istasyona varış zaman1

$d_{\text {is }} \quad i$ numaralı trenin $s$ numaralı istasyondan kalkış zamanı

$t_{i, s, S+1} i$ numaralı doğu yönlü trenin $s$ numaralı istasyon ile $s+1$ numaralı istasyon arasındaki seyir suresi.

$t_{j, s+1, s} j$ numaralı batı yönlü trenin $s+1$ numaralı istasyon ile $s$ numaralı istasyon arasındaki seyir suresi.

$k_{i} \quad i$ numaralı doğu yönlü trenin 1 numaralı istasyondan sisteme giriş zamanı

$k_{j} \quad j$ numaralı batı yönlü trenin 5 numaralı istasyondan sisteme giriș zamanı

$v_{i} \quad i$ numaralı doğu yönlü trenin 5 numaralı istasyon için planlanmış varış zamanı

$v_{j} \quad j$ numaralı batı yönlü trenin 1 numaralı istasyon için planlanmış varış zamanı

$e_{i} \quad i$ numaralı doğu yönlü trenin 5 numaralı istasyona ulaştığındaki gecikmesi

$e_{j} \quad j$ numaralı batı yönlü trenin 1 numaralı istasyona ulaştığındaki gecikmesi

$c_{i s j} \quad i$ numaralı doğu yönlü tren $j$ numaralı batı yönlü trenden önce $s$ ve $s+1$ numaralı istasyonlar arasındaki hat kesimine giriş yapıyorsa 1, aksi takdirde 0 değerini alan bir $0-1$ değişkeni 
$b_{j s m} \quad j$ numaralı batı yönlü tren m numaralı batı yönlü trenden $(j<m)$ önce $s$ ve $s+1$ numaralı istasyonlar arasındaki hat kesimine giriş yapıyorsa 1 , aksi takdirde 0 değerini alan bir 0-1 değişkeni

$b_{\text {isk }} \quad i$ numaralı doğu yönlü tren $k$ numaralı doğu yönlü trenden $(i<k)$ önce $s$ ve $s+1$ numaralı istasyonlar arasındaki hat kesimine giriş yapıyorsa 1 , aksi takdirde 0 değerini alan bir 0-1 değișkeni olarak tanımlanmıştır.

Buna göre, tamsayılı programlama modeli aşağıdaki gibi oluşturulmuştur:

$\operatorname{Min} \sum e_{i}+\sum e_{j}$

Kisitlar:

Başlangıç istasyonundan kalkış kısıtları:

$d_{i l} \geq k_{i} \quad i \in E, \quad l \in S$

$d_{j s} \geq k_{j} \quad j \in W, \quad s \in S$

Son istasyona varış ve gecikme tanımı kısıtları:

$a_{i s}-e_{i}=v_{i} \quad i \in E, \quad s \in S$

$a_{j 1}-e_{j}=v_{j} \quad j \in W, \quad l \in S$

Ardışık istasyonlar arasındaki seyir süresi kısıtları:

$\begin{gathered}a_{i, s+1}-d_{i s}=t_{i, s+1} \\ \quad s \in\{1, \ldots, s-1\} \\ a_{j s}-d_{j, s+1}=t_{j, s+1} \\ s \in\{1, \ldots, s-1\}\end{gathered} j \in W$,

İstasyonlarda duruş süresi kısıtları:

$\begin{array}{cc}d_{i s}-a_{i s} \geq 1 & s \in\{1, \ldots, s-1\} \\ d_{j s}-a_{j s} \geq 1 & j \in W, \\ & s \in\{2, \ldots, s\}\end{array}$

Buluşma (Karşılaşma) Kısıtları:

$\begin{gathered}d_{i s}-a_{j s}+120 c_{i s j} \geq 2 \\ s \in\{1, \ldots, s-1\} \\ d_{j, s+1}-a_{i, s+1}-120 c_{i s j} \geq-118 \\ s \in\{1, \ldots, s\}\end{gathered} \quad i \in E, \quad j \in W$,

İzleme ve öne geçme kısıtları - kalkışlar için:

$d_{j, s+1}-d_{m, s+1}+120 b_{j s k} \geq 5 \quad j, m \in W, s \in$

$\{1, \ldots, s-1\} \quad j<m$

$d_{k, s+1}-d_{j, s+1}-120 b_{j s k} \geq-115 \quad j, m \in$

$W, s \in\{1, \ldots, s-1\} \quad j<m$

İzleme ve öne geçme kısıtları - varışlar için:

$a_{j s}-a_{m s}+120 b_{j s m} \geq 2 \quad j, m \in W, s \in$

$\{1, \ldots, s-1\} \quad j<m$

$a_{m s}-a_{j s}-120 b_{j s m} \geq-118 \quad j, m \in W, s \in$

$\{1, \ldots, s-1\} \quad j<m$

$c_{i s j}-c_{i, s+1, j} \geq 0 \quad i \in E, \quad j \in W$ $s \in\{1, \ldots, s-1\}$

$b_{j s m}-b_{j, s-1, m} \geq 0 \quad j, m \in W, \quad s \in$

$\{2, \ldots, s\} \quad j<m$

İzleme ve öne geçme kısıtları - kalkışlar için:

$d_{i s}-d_{k s}+120 b_{i s k} \geq 5 \quad i, k \in E, s \in S$ $i<k$

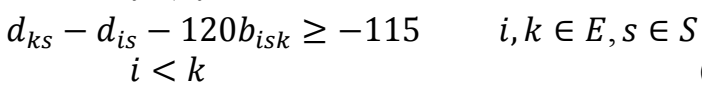

İzleme ve öne geçme kısıtları - varışlar için:

$a_{i, s+1}-a_{k, s+1}+120 b_{i s k} \geq 2 \quad i, k \in E, s \in S$ $a_{k, s+1}-a_{i, s+1}-120 b_{i s k} \geq-118$

$i, k \in E$,

$$
s \in S \quad i<k
$$

Mükerrer öne geçmeyi yasaklama kısıtları:

$b_{i s k}-b_{i, s+1, k} \geq 0 \quad i, k \in E, s \in S$ $i<k$

$c_{i s j}-c_{i, s+1, j} \geq 0 \quad i \in E, \quad j \in W$ $s \in\{1, \ldots, s-1\}$

$b_{j s m}-b_{j, s-1, m} \geq 0 \quad j, m \in W, \quad s \in$

$\{2, \ldots, s\} j<m$

Pozitiflik ve tamsayı kısıtları:

Tüm değişkenler 0 veya pozitif

$c_{i s j}, b_{j s m}, b_{i s k} \in\{0,1\}, i \in E, s \in S, j \in W$

$\mathrm{Bu}$ modelde; (1) amaç fonksiyonudur ve bu amaç fonksiyonuyla sistemdeki tüm trenlerin son varış noktalarındaki gecikmelerinin toplamı en aza indirilmek istenmektedir. (2) ve (3), trenlerin hatta (kontrol bölgesine) giriş zamanlarını belirtmektedirler. $\mathrm{Bu}$ kisitlar uyarınca trenler, başlangıç istasyonlarından belirtilen zamandan önce hareket edemezler. Ancak çatışma çözümleri nedeniyle başlangıç istasyonlarında bekletilmeleri söz konusu olabilir. (4) ve (5), her tren için, amaç fonksiyonunda yer alan gecikme değerini varış istasyonuna gerçek varış zamanı ile planlanan varış zamanı arasındaki farka eşitleyen kısıt fonksiyonudur. $\mathrm{Bu}$ kısıt fonksiyonları, doğrusal karışık tamsayı programlarındaki tüm değişkenlerin varsayılan özelliği olan pozitiflik ile birleştiğinde, trenlerin son varış istasyonlarına planlanan varış zamanlarına göre daha erken varmalarını da engelleyici bir nitelik kazanmaktadır. (6) ve (7), trenlerin ardışık istasyonlar arası seyir sürelerini Tablo 1'deki ilgili değerlere eşitlemek için kullanılan kısıt fonksiyonlarıdır. (8) ve (9), bir trenin bir istasyondan kalkışının o istasyona varışından önce olmamasını, eğer o istasyonda planlanmış duruş varsa, izin verilen en küçük duruş süresi kadar durmasını garanti eden kısıt fonksiyonlarıdır; doğuya ve batıya giden trenler için ayrı ayrı tanımlanmışlardır. (10) ve (11), bir buluşma istasyonuna bir trenin varışından en az 2 dakika sonra aynı istasyondan zit yönlü bir başka trenin ayrılabilmesi koşulunu getiren kısıt fonksiyonlarıdır. İlgili 0-1 değişkeni, ilgili istasyon ile başlayan hat kesimine hangi trenin önce gireceğini belirlemektedir. Kısıtların ikisi de hiçbir zaman ihlal edilmeyecek olmakla birlikte, ilgili hat kesimine batı yönlü tren önce giriyorsa (10), doğu yönlü tren önce giriyorsa (11) aktif olacaktır. (12) ve (13), bir istasyondan bir trenin hareketinden en az 5 dakika sonra aynı istasyondan aynı yöne giden bir başka trenin hareket edebilmesi koşulunu getiren kısıt fonksiyonlardır. İlgili 0-1 değişkeni, ilgili istasyon ile başlayan hat kesimine hangi trenin önce gireceğini belirlemektedir. Kısıtların hiçbiri hiçbir zaman ihlal edilmeyecek olmakla birlikte, ilgili hat kesimine büyük numaralı tren önce giriyorsa $\geq 5$, küçük numaralı tren önce giriyorsa $\geq-115$ şeklindeki kısıtlar aktif olacaktır. (14) ve (15) bir istasyona bir trenin varışından en az 2 dakika sonra aynı istasyona aynı yönde giden bir 
trenin varış yapabilmesi koşulunu getiren kısıt fonksiyonlardır. İlgili 0-1 değişkeni, ilgili istasyon ile başlayan hat kesimine hangi trenin önce gireceğini belirlemektedir. Kısıtların hiçbiri, hiçbir zaman ihlal edilmeyecek olmakla birlikte ilgili hat kesimine büyük numaralı tren önce giriyorsa $\geq 2$, küçük numaralı tren önce giriyorsa $\geq-118$ şeklindeki kısıtlar aktif olacaktır.(16) ve (17), zit yönlerde ilerleyen trenlerin yalnızca 1 kere buluşabilmesini ve aynı yönlerde ilerleyen trenlerin arasında yalnızca 1 kere öne geçme olabilmesini garanti eden kısıtlardır. Bu kısıtlar, uygun dal sayısını azaltarak çözüm süresini kısaltma amaciyla yazılmıştır. Bu kısıtlar olmadan da model aynı çözümü üretir; ancak çözüm süresi daha uzun olur.(18) ve (19), bir istasyondan bir trenin hareketinden en az 5 dakika (varsayılan) sonra aynı istasyondan aynı yöne giden bir başka trenin hareket edebilmesi koşulunu getiren kısıt fonksiyonlardır. İlgili 0-1 değişkeni, ilgili istasyon ile başlayan hat kesimine hangi trenin önce gireceğini belirlemektedir. Kısıtların hiçbiri hiçbir zaman ihlal edilmeyecek olmakla birlikte, ilgili hat kesimine büyük numaralı tren önce giriyorsa $\geq 5$, küçük numaralı tren önce giriyorsa $\geq-115$ şeklindeki kısıtlar aktif olacaktır.(20) ve (21), bir istasyona bir trenin varışından en az 2 dakika sonra aynı istasyona aynı yönde giden bir trenin varış yapabilmesi koşulunu getiren kısıt fonksiyonlardır. İlgili 0-1 değişkeni, ilgili istasyon ile başlayan hat kesimine hangi trenin önce gireceğini belirlemektedir. Kısıtların hiçbiri hiçbir zaman ihlal edilmeyecek olmakla birlikte ilgili hat kesimine büyük numaralı tren önce giriyorsa $\geq 2$, küçük numaralı tren önce giriyorsa $\geq-118$ şeklindeki kisıtlar aktif olacaktır.(22), (23) ve (24), aynı yönlerde ilerleyen trenlerin arasında yalnızca 1 kere öne geçme olabilmesini garanti eder. (25), trenlerin istasyon aralığındaki izleme sırası değişkenlerini 0 ya da 1 olmaya zorlayan kisit fonksiyonudur.

(26), karışık tamsayı programlama modellerinin değişmez özelliği olan tüm değişkenlerin 0'dan büyük ya da 0’a eşit olmasını garanti eden kısıt fonksiyonudur.

\section{4. ÖRNEK UYGULAMA (A CASE STUDY)}

Kayseri-Kars demiryolu hattı Şekil 1.'de verilmiştir. Yeniçubuk-Çetinkaya güzergahının seçilmesinin sebebi; Kayseri-Kars hattının tamamen incelenerek en çok çatışmanın 6 trenin çalıştığ Yeniçubuk-Çetinkaya arasında olduğunun görülmesinden dolayıdır. Çetinkaya istasyonundan sonra tren sayısı ikiye düşmektedir.

Tek hatlı Kayseri-Kars demiryolu hattının Yeniçubuk istasyonundan Çetinkaya istasyonuna kadar olan 16 istasyonlu bölümü incelenmiştir. $\mathrm{Bu}$ güzergahta karşılıklı olarak Doğu Ekspresi, Kurtalan (Güney) Ekspres ve 4 Eylül Mavi tren tiplerinin her birinden 2 tane olmak üzere toplam 6 tren birlikte çalışmaktadır. İstasyonlar arası bağlantı yolları tek hatlı olduğu için, birbirine zit yönlerde ilerleyen trenlerin istasyonlarda buluşma yapması gerekmektedir. $\mathrm{Bu}$ uygulamada, toplam bekleme süresini minimize etmek için kalkış saatleri ayarlamasıyla trenlerin birbirini beklemelerinden oluşan zaman kayıplarının enazlanmasına çalışılacaktır.

Yeniçubuk-Çetinkaya demiryolu hattında gerçek verilere dayalı planlama yapılmıştır. Bu hatta 6 tren ve 16 istasyon bulunmaktadır. Sayısal uygulamada istasyonlar; 1. Yeniçubuk, 2. İhsanlı, 3. Şarkışla, 4. Gücük, 5. Hanlı, 6. Gözmen, 7. Bedirli, 8. Kalın, 9. Yap1, 10. Sivas, 11. Bostankaya, 12. Eskiköy, 13. Karagöl, 14. Bozarmut, 15. Kangal, 16. Çetinkaya olarak numaralandırılmıştır. Demiryolu hattı, aynı istikamette ve ters istikamette seyir halinde olan trenlerin aynı parça üzerinde yol aldıkları tek hatlı demiryolu hattıdır. Trenlerin kalkış ve varış noktaları 1 ve 16 numaralı istasyonlardir.

1 numaralı istasyondan 16 numaralı istasyona doğru seyretmekte olan trenler, doğuya giden trenler; 16

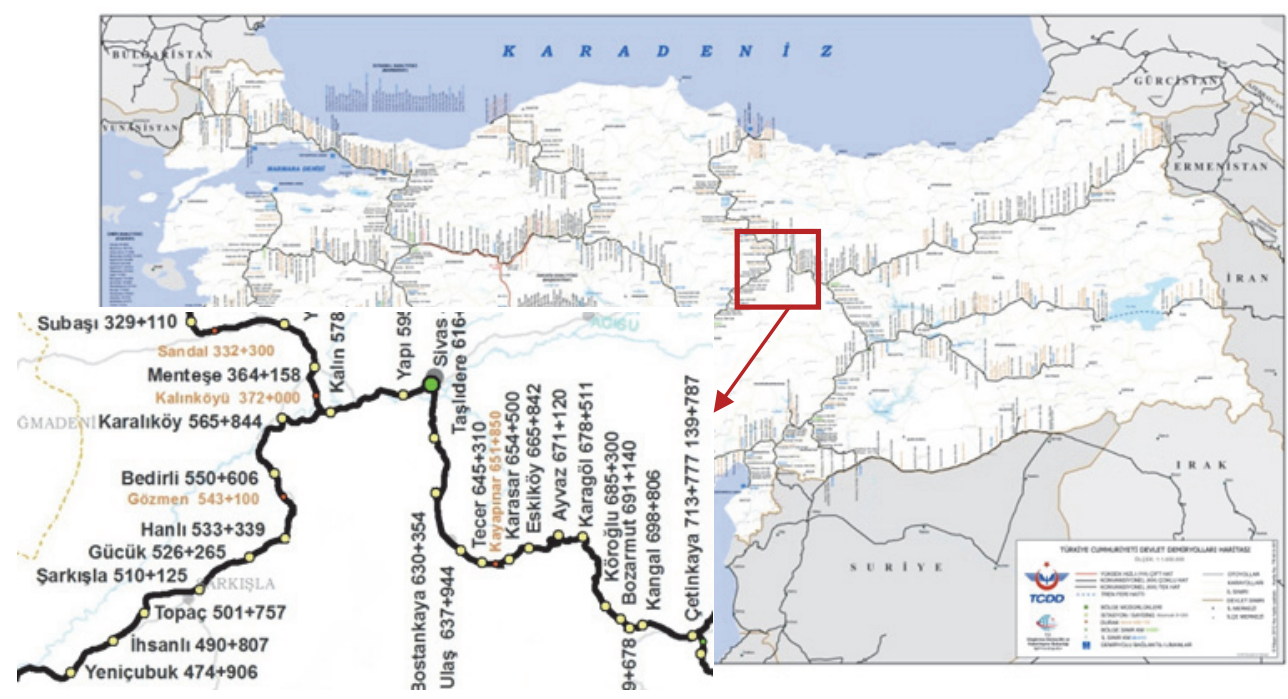

Şekil 1. Yeniçubuk-Çetinkaya demiryolu hattı (Yeniçubuk-Çetinkaya railway) 
numaralı istasyondan 1 numaralı istasyona doğru seyretmekte olan trenler ise batiya giden trenler olarak sınıflandırılmıştır. Doğuya giden trenler kalkış istasyonundan kalkış sırasına göre; Doğu Ekspresi (1), Kurtalan (Güney) Ekspresi (2), 4 Eylül Mavi (3) olarak; batıya giden trenler ise kalkış istasyonundan kalkış sırasına göre Doğu Ekspresi (4), 4 Eylül Mavi (5), Kurtalan (Güney) Ekspresi (6) olarak numaralandırılmıştır. Tablo 1'de trenlerin istasyonlar arası seyir süreleri verilmiştir. Trenlerin istasyonlarda planlanmış duruşları ana istasyonlarda (Sivas) $5 \mathrm{dk}$. ve bazı ara istasyonlarda 1 dk'dır. Diğer ara istasyonlarda ise trenler durmadan geçmektedir. Tablo 2'de trenlerin başlangıç istasyonlarından kalkış saatleri, planlanmış duruş süreleri ve planlanmış seyir süreleri verilmiştir.

Tablo 1. Ardışık istasyonlar arası seyir süreleri (dakika) (Transit time between stations (minute))

\begin{tabular}{cccc}
\hline $\begin{array}{c}\text { İstasyon } \\
\text { aralığ1 }\end{array}$ & $\begin{array}{c}\text { Doğu } \\
\text { Ekspresi }\end{array}$ & $\begin{array}{c}\text { Kurtalan } \\
\text { (Güney) } \\
\text { Ekspresi }\end{array}$ & $\begin{array}{c}\text { 4 Eylül } \\
\text { Mavi }\end{array}$ \\
\hline $1-2$ & 13 & 14 & 16 \\
$2-3$ & 16 & 17 & 20 \\
$3-4$ & 13 & 14 & 16 \\
$4-5$ & 6 & 6 & 7 \\
$5-6$ & 8 & 9 & 10 \\
$6-7$ & 6 & 6 & 7 \\
$7-8$ & 22 & 24 & 28 \\
$8-9$ & 6 & 6 & 7 \\
$9-10$ & 6 & 6 & 7 \\
$10-11$ & 22 & 24 & 28 \\
$11-12$ & 28 & 30 & 35 \\
$12-13$ & 10 & 11 & 13 \\
$13-14$ & 10 & 11 & 13 \\
$14-15$ & 6 & 6 & 7 \\
$15-16$ & 12 & 13 & 15 \\
\hline Toplam & 184 & 197 & 229 \\
\hline
\end{tabular}

Tablo 2. Trenlerin planlanmış duruş süreleri ve planlanmış seyir süreleri (Trains scheduled down times and scheduled cruise time)

\begin{tabular}{ccccc}
\hline Trenler & $\begin{array}{c}\text { Kalkış } \\
\text { İstasyonu }\end{array}$ & $\begin{array}{c}\text { Kalkış̧ } \\
\text { Zamanı } \\
\text { poynca } \\
\text { planlanmış } \\
\text { duruş } \\
\text { süresi } \\
\text { toplamı } \\
(\mathrm{dk})\end{array}$ & $\begin{array}{c}\text { Hat } \\
\text { boyunca } \\
\text { planlanmış } \\
\text { seyir } \\
\text { süreleri } \\
(\mathrm{dk})\end{array}$ \\
\hline (1) & Yeniçubuk & $02: 58$ & 11 & 195 \\
$(2)$ & Yeniçubuk & $20: 04$ & 16 & 213 \\
$(3)$ & Yeniçubuk & $23: 12$ & 11 & 240 \\
(4) & Çetinkaya & $04: 00$ & 12 & 196 \\
(5) & Çetinkaya & $17: 37$ & 12 & 241 \\
(6) & Çetinkaya & $21: 26$ & 15 & 212 \\
\hline
\end{tabular}

İstasyonlar arası bağlantı yolları tek hatlı olduğu için, birbirine zit yönlerde ilerleyen trenlerin istasyonlarda buluşma yapması gerekmektedir. Benzer şekilde, bir trenin aynı yönde ilerleyen ve kendisinden daha yavaş olan bir trenin önüne geçebilmesi ancak istasyonlardan bir tanesinde yavaş trenin hızlı trene yol vermesiyle mümkün olacaktır. Trenlerin başlangıç istasyonlarından kalkış zamanları, modelde sisteme giriş zamanları olarak girilecek ve çatışmalar çözülerek trenlerin son istasyonlarına vardıklarında gecikmeleri toplamı en küçüklenmeye çalışılacaktır.

Bütün ara istasyonlarda yeterli sayıda barınma yeri bulunmaktadır. Trenler için kalkış-varış süreleri esasen istasyon uzunluğuna, tren uzunluğuna, trenlerin hızlanma ve frenleme yetilerine, istasyon bölgesindeki hattın eğim, kurp gibi hat direnimlerine etki edecek geometrik özelliklerine ve trafik kontrol (sinyalizasyon) sisteminin özelliklerine göre değişkenlik göstermektedir. Zit yönlerde ilerleyen trenler için varış - kalkış en az 2 dakika ve aynı yönde ilerleyen trenler için kalkış-kalkış en az 5 dakika olarak belirlenmiştir.

6 karar değişkenli, 1293 kısıtlı problem modeli, Lindo 6.1 kullanılarak çözülmüştür. Sonuç olarak, hatta çalışan trenlerin birbirini beklemelerinden oluşan gecikme süreleri toplamının $37 \mathrm{dk}$. olduğu görülmüştür. Sonuçlar, Tablo 3'de mevcut durum çizelgesi ve Tablo 4'te de optimal çizelge olarak verilmiştir.

Tablo 3. Mevcut durum çizelgesi (Current status schedule)

\begin{tabular}{lllll}
\hline $\begin{array}{l}\text { Tren } \\
\text { No }\end{array}$ & $\begin{array}{l}\text { Kalkış } \\
\text { İstasyonu }\end{array}$ & $\begin{array}{l}\text { Varış } \\
\text { İstasyonu }\end{array}$ & $\begin{array}{l}\text { Kalkış } \\
\text { saati }\end{array}$ & $\begin{array}{l}\text { Varış } \\
\text { saati }\end{array}$ \\
\hline$(1)$ & Yeniçubuk & Çetinkaya & $02: 58$ & $06: 59$ \\
$(2)$ & Yeniçubuk & Çetinkaya & $20: 04$ & $00: 30$ \\
$(3)$ & Yeniçubuk & Çetinkaya & $23: 12$ & $03: 09$ \\
$(4)$ & Çetinkaya & Yeniçubuk & $04: 00$ & $08: 13$ \\
$(5)$ & Çetinkaya & Yeniçubuk & $17: 37$ & $21: 36$ \\
$(6)$ & Çetinkaya & Yeniçubuk & $21: 26$ & $01: 43$ \\
\hline
\end{tabular}

Tablo 4. Optimal çizelge (Optimal Schedule)

\begin{tabular}{lllll}
\hline $\begin{array}{l}\text { Tren } \\
\text { No }\end{array}$ & $\begin{array}{l}\text { Kalkış } \\
\text { İstasyonu }\end{array}$ & $\begin{array}{l}\text { Varış } \\
\text { İstasyonu }\end{array}$ & $\begin{array}{l}\text { Kalkışs } \\
\text { saati }\end{array}$ & $\begin{array}{l}\text { Varış } \\
\text { saati }\end{array}$ \\
\hline (1) & Yeniçubuk & Çetinkaya & $03: 05$ & $06: 21$ \\
$(2)$ & Yeniçubuk & Çetinkaya & $20: 04$ & $23: 56$ \\
$(3)$ & Yeniçubuk & Çetinkaya & $23: 12$ & $03: 12$ \\
$(4)$ & Çetinkaya & Yeniçubuk & $04: 00$ & $07: 16$ \\
$(5)$ & Çetinkaya & Yeniçubuk & $17: 37$ & $21: 46$ \\
$(6)$ & Çetinkaya & Yeniçubuk & $21: 26$ & $01: 07$ \\
\hline
\end{tabular}


Tablo 5. Mevcut durum ile optimal durumun karşılaştırılması (Comparing the current situation with the optimal situation)

\begin{tabular}{|c|c|c|c|c|c|c|c|c|c|}
\hline \multirow[b]{2}{*}{$\begin{array}{l}\text { Tren } \\
\text { No }\end{array}$} & \multirow{2}{*}{$\begin{array}{c}\text { Planlanan } \\
\text { Seyahat } \\
\text { Süresi (dk) }\end{array}$} & \multicolumn{4}{|c|}{ Mevcut Durum } & \multicolumn{4}{|c|}{ Optimal Durum } \\
\hline & & $\begin{array}{c}\text { Kalkış } \\
\text { Saati }\end{array}$ & $\begin{array}{l}\text { Varış } \\
\text { Saati }\end{array}$ & $\begin{array}{c}\text { Planlanan } \\
\text { Varış } \\
\text { Saati }\end{array}$ & $\begin{array}{l}\text { Gecikme } \\
\text { Süresi } \\
(\mathrm{dk})\end{array}$ & $\begin{array}{c}\text { Kalkış } \\
\text { Saati }\end{array}$ & $\begin{array}{l}\text { Varış } \\
\text { Saati }\end{array}$ & $\begin{array}{c}\text { Planlanan } \\
\text { Varış } \\
\text { Saati }\end{array}$ & $\begin{array}{c}\text { Gecikme } \\
\text { Süresi } \\
\text { (dk) }\end{array}$ \\
\hline (1) & 195 & $02: 58$ & $06: 59$ & $06: 13$ & 46 & 03:05 & $06: 21$ & $06: 20$ & 1 \\
\hline (2) & 213 & $20: 04$ & $00: 30$ & $23: 37$ & 53 & $20: 04$ & $23: 56$ & $23: 37$ & 19 \\
\hline (3) & 240 & $23: 12$ & $03: 12$ & $03: 12$ & 0 & $23: 12$ & $03: 12$ & $03: 12$ & 0 \\
\hline (4) & 196 & 04:00 & $08: 13$ & $07: 16$ & 57 & 04:00 & $07: 16$ & $07: 16$ & 0 \\
\hline (5) & 241 & $17: 37$ & $21: 38$ & $21: 38$ & 0 & $17: 37$ & $21: 46$ & $21: 38$ & 8 \\
\hline (6) & 212 & $21: 26$ & $01: 43$ & $00: 58$ & 45 & $21: 26$ & 01:07 & $00: 58$ & 9 \\
\hline
\end{tabular}

Mevcut durum çizelgesi ile optimal çizelge, gerçek verilere göre belirlenen hat boyunca trenlerin seyahat süresi açısından karşılaştırılarak, her tren için iki durumda da gecikme süreleri Tablo 5' de verilmiştir. Mevcut durumda trenlerin hattaki toplam gecikmeleri 3 saat $21 \mathrm{dk}$. iken optimal durumdaki toplam gecikme $37 \mathrm{dk}$. olmaktadır. Yani gecikme süresinin toplamda 2 saat $44 \mathrm{dk}$. azaldığı görülmektedir.

Benzetim; teorik ya da fiziksel gerçek bir sistemin, bilgisayar ortamında modellendikten sonra bu model ile sistemin işletilmesi amacına yönelik olarak, sistemin davranışını anlayabilmeyi sağlayan veya değişik stratejileri değerlendirebilmek için deneyler yürüten, bu sistemlerin özelliklerini ve davranışlarını bilgisayar aracılığıyla değerlendiren bir tekniktir. Arena, modelleme ve benzetim problemlerinin çözümünde büyük yeteneğe sahip bir yazılım programıdır. Benzetim ve modelleme işlemlerini adım adım tanımlama ve karar vermeye yardımcı olacak benzetim sonuçlarını gösterir. Ön görülen bir sistemin tasarım aşamasında iken gerçeklendiğinde nasıl davrandığını görme veya mevcut sistemlerde sistemin performansinı anlama, benzetimi yapılan sistemin gelecekteki performansına ait karmaşık ilişkileri anlama, hareketli animasyon grafikleri ile yapılan benzetimi canlandırma için kullanılabilmektedir.

Kalkış saatlerindeki değişimler ile yeniden yapılan Tablo 4 optimal çizelge'deki kalkış saati verileri, trenlerin istasyonlar arası seyir süreleri ve trenlerin istasyonlarda bekleme süreleri Arena komutları ile sisteme girilmiştir. Sistemin başlangıç noktası olarak hatta çalışan 6 trenin her biri için kalkış istasyonlarından kalkış zamanları benzetim modeline 'create modülü' ile girilmiştir. Her tren için ayrı modül oluşturulmuştur ve görsel açıdan tamamlanması amaciyla 'entity veri modülü' ile resim ataması yapılmıştır. Hatta 16 istasyon bulunduğundan her istasyon için 'station modülü' ile istasyon belirteci oluşturulmuş ve 'process modülü' ile trenlerin istasyonlarda bekleme süreleri sisteme girilmiştir. Trenlerin yol aldığı istasyonlar ayrı ayrı 'route modülü' ile birbirine bağlanarak tren rotaları belirlenmiştir. Karşılıklı trenlerde istasyonlar arası çatışma olmaması için ardışı iki istasyon arasında karşılaşması muhtemel trenler için 'decide modülü' ile trenlerin öncelikli geçiş ataması yapılmıştır. Benzetim çalışır halde iken gözlem değerlerinin istatistiklerini tutmak amaciyla 'record modülü' kullanılmıştır. Son olarak 'dispose modülü' ile trenlerin varış noktaları belirlenmiştir. Benzetim programı Arena 13.5 ile şu sonuçlara varılmıştır:

$>\quad$ Sayisal uygulamada (2) nolu tren olarak adlandırılan Yeniçubuk istasyonundan Çetinkaya istikametine doğru hareket eden Kurtalan (Güney) Ekspres treni ile (5) nolu tren olarak adlandırılan Çetinkaya istasyonundan Yeniçubuk istikametine doğru yol alan 4 Eylül Mavi treninin 3. istasyon olan Şarkışla istasyonu ile 4. istasyon olan Gücük istasyonu arasında karşılaşmaması için 4 Eylül mavi trenin 5. istasyonunda beklemesi gerekmektedir. Şarkışla-Gücük istasyonları arası $16 \mathrm{~km}$ bir hattan ibarettir. Trenlerin karşılaşma noktaları da Gücük istasyonundan itibaren Şarkışla istasyonuna doğru 8 km'lik bir hatta denk gelmektedir. Koşulların uygun olması halinde, bu bölüme $8 \mathrm{~km}$ 'lik ikinci hattın yapılmasının trenlerin beklemesini önleyeceği düşüncesine varılmıştır.

(2) nolu tren olarak adlandırılan Yeniçubuk istasyonundan Çetinkaya istikametine doğru hareket eden Kurtalan (Güney) Ekspres treni ile (6) nolu tren olarak adlandırılan Çetinkaya istasyonundan Yeniçubuk istikametine doğru yol alan Kurtalan (Güney) Ekspres treninin 11. istasyon olan Bostankaya istasyonu ile 12. istasyon olan Eskiköy istasyonu arasında karşılaşmaması için (2) nolu Kurtalan (Güney) Ekspres treninin Bostankaya istasyonunda beklemesi gerekmektedir. BostankayaEskiköy istasyonları aras1 $35 \mathrm{~km}$ bir hattan ibarettir. Trenlerin karşılaşma noktaları ise Bostankaya istasyonundan itibaren Eskiköy istasyonuna doğru 18 km'lik bir hatta denk gelmektedir. Koşulların uygun olması halinde, bu bölüme 18 km'lik ikinci hattın yapılmasının trenlerin beklemesini önleyeceği düşüncesine varılmıştır. 
(3) nolu tren olarak adlandırılan Yeniçubuk istasyonundan Çetinkaya istikametine doğru hareket eden 4 Eylül Mavi treni ile (6) nolu tren olarak adlandırılan Çetinkaya istasyonundan Yeniçubuk istikametine doğru yol alan Kurtalan (Güney) Ekspres treninin 4. istasyon olan Gücük istasyonu ile 5. istasyon olan Hanlı istasyonu arasında karşılaşmaması için (6) nolu Kurtalan (Güney) Ekspres treninin Hanlı istasyonunda beklemesi gerekmektedir. Gücük-Hanlı istasyonları aras $17 \mathrm{~km}$ bir hattan ibarettir. Trenlerin karşılaşma noktaları ise Hanlı istasyonundan itibaren Gücük istasyonuna doğru $5 \mathrm{~km}$ 'lik bir hatta denk gelmektedir. Koşulların uygun olması halinde, bu bölüme $5 \mathrm{~km}$ 'lik ikinci hattın yapılmasının trenlerin beklemesini önleyeceği düşüncesine varılmıştır.

İncelenen 240 km'lik Yeniçubuk-Çetinkaya hattında trenlerin birbirinin geçişini beklemesinden kaynaklanan toplam $37 \mathrm{dk}$ 'lık gecikmenin, koşulların uygun olması halinde hattın yukarıda belirtilen $31 \mathrm{~km}$ kısımlarına ikinci hat yapılarak $30 \mathrm{dk}$. azaltılacağ benzetim uygulanması kullanılarak gösterilmiştir. Matematiksel modelin sonucuna göre yapılan 1 . benzetim modelinin ve belirli kısımlara ikinci hat yapıldıktan sonraki 2 . benzetim sonuçları ise Tablo 6'da verilmiştir.

Tablo 6. Benzetim modellerinin sonuçlarının karşılaştırılması (Comparison of simulation models' results)

\begin{tabular}{|c|c|c|}
\hline Expression & $\begin{array}{c}\text { Ortalama } \\
(\mathrm{dk}) \\
(1 . \\
\text { benzetim) }\end{array}$ & $\begin{array}{c}\text { Ortalama } \\
(\mathrm{dk}) \\
(2 . \\
\text { benzetim) }\end{array}$ \\
\hline $\begin{array}{c}\text { 1. Trenin son } \\
\text { istasyona varış süresi }\end{array}$ & 4701,00 & 4701,28 \\
\hline $\begin{array}{l}\text { 2. Trenin son } \\
\text { istasyona varış süresi }\end{array}$ & 5756,00 & 5740,28 \\
\hline $\begin{array}{l}\text { 3. Trenin son } \\
\text { istasyona varıș süresi }\end{array}$ & 5952,00 & 5951,28 \\
\hline $\begin{array}{l}\text { 4. Trenin son } \\
\text { istasyona varış süresi }\end{array}$ & 4756,00 & 4756,24 \\
\hline $\begin{array}{l}\text { 5. Trenin son } \\
\text { istasyona varış süresi }\end{array}$ & 5626,00 & 5618,24 \\
\hline $\begin{array}{l}\text { 6. Trenin son } \\
\text { istasyona varış süresi }\end{array}$ & 5827,00 & 5820,24 \\
\hline
\end{tabular}

Arena 13.5 ile 240 km'lik hattın 31 km'lik kısmında ikinci hat olması durumu incelenmiştir ve gecikmeler bazında sonuçlar Tablo 7'de verilmiştir.

Tablo 7'ye göre mevcut durumda hatta toplam 3 saat $21 \mathrm{dk}$ 'lk gecikmenin 37 dk'ya indirilmesi ile hatta toplam \% 81,6 oranında verimlilik sağlanmıştır.

Koşulların uygun olması halinde belirli kısımlara ikinci hat yapıldıktan sonra ise gecikmeler toplamı 37 dk dan 7 dk'ya indirilerek \% 81,1 oranında verimlilik sağlanmıştır. Son durumda mevcut duruma göre \% 96,5 oranında verimlilik sağlanmıştır.

\section{SONUÇLAR (CONCLUSIONS)}

$\mathrm{Bu}$ çalışmada, demiryolu işletmeciliğinin en önemli konularından olan tren çizelgelemesi üzerinde durulmuştur. Demiryolu çizelgeleme ile ilgili kaynaklar ayrıntılı bir şekilde incelenmiştir, konunun önemi vurgulanmaya çalışılarak yöntemlerinden bahsedilmiştir ve konuyla ilgili bir örnek uygulama yapılmıştır.

Önerilen 0-1 tamsayılı matematiksel model, gerçek verilerle Kayseri-Kars demiryolu hattının bir bölümü olan Yeniçubuk-Çetinkaya hat kesimi üzerinde uygulanmıştır. 16 istasyonu 6 trenin çalıştığı bu hat çatışmanın en çok olduğu bölüm olması sebebiyle tercih edilmiştir. Bu hattaki trenlerin 3 saat 21 dakika olan toplam gecikme süresi, ilk olarak tren hareket saatlerinin düzenlenmesi ile $37 \mathrm{dk}$ 'ya indirilerek \% 81,59 oranında iyileşme sağlanmış ve benzetim programı Arena 13.5 ile incelenmiştir. Uygun koşullarda $240 \mathrm{~km}$ 'lik hattın gecikmelere neden olan 31 km'lik kısmının çift hatta dönüştürülmesi durumunda gecikme süresi 7 dk'ya indirilerek toplamda \% 96,52 oranında iyileştirme olacağ1 benzetim çalışması ile gösterilmiştir.

Bu çalışmada 240 km'lik hat ele alınmıştır. Bundan sonraki çalışmalarda daha uzun hatlar ele alınabileceği gibi, Türkiye'deki tüm hat ele alınarak çözüm yaklaşımları geliştirilebilir. Ancak problemin boyutu büyüyeceğinden optimal çözümleri bulmak mümkün olamayacağı görülmektedir. Bunun için optimuma yakın çözümler veren sezgisel yaklaşımlara ihtiyaç olacağı düşünülmektedir.

Tablo 7. Sonuç tablosu (The result table)

\begin{tabular}{ccc}
\hline Tren no & $\begin{array}{c}\text { Mevcut durumda } \\
\text { Gecikmeler (dk) }\end{array}$ & $\begin{array}{c}\text { Matematiksel modelin sonucı } \\
\text { göre gecikmeler (dk) }\end{array}$ \\
\hline$(1)$ & 46 & 1 \\
$(2)$ & 53 & 19 \\
$(3)$ & 0 & 0 \\
$(4)$ & 57 & 0 \\
$(5)$ & 0 & 8 \\
$(6)$ & 45 & 9 \\
\hline TOPLAM & 201 & 37
\end{tabular}




\section{KAYNAKLAR (REFERENCES)}

1. Eren, T., Güner, E., “A Literature Survey for Multicriteria Scheduling Problems on Single and Parallel Machines", Journal of The Faculty of Engineering and Architecture of Gazi University, 17 (4), 37-69, 2002.

2. Eren, T., "Solving Scheduling Problem with Time Dependent Learning Effect to Number ofTtardy Jobs and Range of Lateness Criteria", Journal of The Faculty of Engineering and Architecture of Gazi University, 27 (4), 875879, 2012.

3. Eren, T., Güner, E., "Minimizing Total Tardiness in a Scheduling Problem with a Learning Effect", Applied Mathematical Modelling, 31 (7), 13511361, 2007.

4. Gültekin, N., Demiryolu Çizelgeleme Probleminin Modellenmesi ve Çözümü, Yüksek Lisans Tezi, Kırıkkale Üniversitesi, Fen Bilimleri Enstitüsü, 2013.

5. Charnes, A., Miller, M.H., "A Model For The Optimal Programming of Railway Freight Train Movements", Purdue University and Carnegie Institute of Technology, 1956.

6. Petersen, E., Taylor, A.J., "A Structured Model for Rail Line Simulation and Optimization", Transportation Science, 16: 2, 192-206, 1982.

7. Kraay, D., Harker, P.T., Chen, B., "Optimal Pacing of Trains in Freight Railroads: Model Formulationand Solution", Operations Research, 39: 1, 82-99, 1991.

8. Higgins, L.F, Kozan, E. "Modelling Single Line Train Operations", Transportation Research Record 1489, Journal of the Transportation Research Board, Railroad TransportationResearch, 9-16, 1995.

9. Cordeau, J.F., Toth, P., Vigo, D., "A Survey of Optimization Models for Train Routing and
Scheduling”, Transportation Science, 32 (4), 380-404, 1998.

10. Linder, T., Zimmermann, U.T., Train Schedule Optimization in Public Rail Transport, Mathematics-Key Technology for the Future: Joint Projects Between Universities and Industry, 703-716, 2000.

11. Caprara, A., Fischetti, M., Toth, P., "Modeling and Solving The Train Timetabling Problem", Operations Research, 150 (5),851-861, 2002.

12. Lee, C., Chen, C., "Scheduling of Train Driver ForTaiwanRailway Administration”, Journal of the Eastern Asia Society for Transportation Studies, 5, 292-306, 2003.

13. Ahuja, K.R., Liu, J., Orlin, B.J., Sharma, D., Shughart, A.L., "Solving Real-Life Locomotive Scheduling Problems, Instituefor Operations Research and Management Sciences", Transportation Science, 39, 503-517, 2005.

14. Chen, C., "Using Integer Programming to Solve the Crew Scheduling Problem in the Taipei Rapid Transit Corporation", Wseas Transactions on Information Science \& Applications, 4: 5, 331341, 2008.

15. Aydın, G., Tren Çizelgelemesi Problemi, Yüksek Lisans Tezi, Yıldız Teknik Üniversitesi, Fen Bilimleri Enstitüsü, İstanbul, 2009.

16. Reimann, M., Nyström, B., "ACO For The Single Line Train Scheduling Problem", Working Paper Series. Institute of Productionand Operations Management University of Graz, 2009.

17. Danescu, E., Integration and Interoperability of Rail Transport in Europe. Implications of The Network in Romania and Moldova, DH 34-08.00. 14-Nord Economy, International Economic Relations, 2013. 